\title{
Acute effects of short term use of ecigarettes on Airways Physiology and Respiratory Symptoms in Smokers with and without Airway Obstructive Diseases and in Healthy non smokers
}

\author{
Anostosios Palamidas ${ }^{1}$, Stomatoula Tsikrika ${ }^{1}$, Paraskevi A. Katsaounou ${ }^{2}$, Sofia Vakali ${ }^{1}$, Sofia-Antiopi \\ Gennimato $^{I}$, George kaltsakas ${ }^{I}$, Christina Gratziou ${ }^{1}$, Nikoloos Koulouris ${ }^{l}$
}

\begin{abstract}
BACKGROUND Although the use of e-cigarettes is increasing worldwide, their short and long-term effects remain undefined. We aimed to study the acute effect of short-term use of e-cigarettes containing nicotine on lung function and respiratory symptoms in smokers with airways obstructive disease (COPD, asthma), "healthy" smokers, and healthy never smokers.

METHODS Respiratory symptoms, vital signs, exhaled NO, airway temperature, airway resistance (Raw), specific airway conductance (sGaw) and single nitrogen breath test were assessed before and immediately after short term use of an e-cigarette containing $11 \mathrm{mg}$ of nicotine among adults with COPD, asthma, "healthy" smokers, and never-smokers. The effect of the use of nicotine-free e-cigarettes among "healthy" never smokers was also studied.

RESULTS The majority of participants reported acute cough. Short term use of nicotine e-cigarettes was associated: a) with increased heart rate in all subjects except in the COPD group, b) decreased oxygen saturation in "healthy" and COPD smokers, c) increased Raw in asthmatic smokers, "healthy" smokers, and healthy never smokers, d) decreased sGaw in healthy subjects, and e) changed slope of phase III curve in asthmatic smokers. Short-term use of nicotine-free e-cigarettes increased Raw and decreased sGaw among healthy never smokers.

concLusions Short-term use of an e-cigarette has acute effects on airways physiology and respiratory symptoms in COPD smokers, asthmatic smokers, "healthy" smokers and healthy never smokers. E-cigarette use was associated with effects in "healthy" never smokers irrespectively of nicotine concentration. More studies are needed to investigate both short and long-term effects of e-cigarette use
\end{abstract}

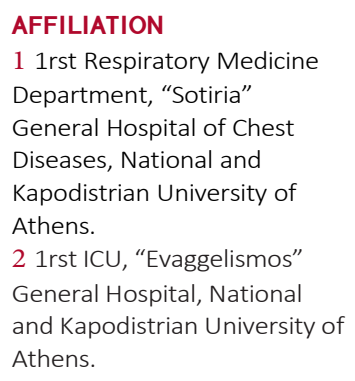

AFFILIATION

1 1rst Respiratory Medicine Department, "Sotiria" General Hospital of Chest Diseases, National and Kapodistrian University of Athens.

2 1rst ICU, "Evaggelismos" General Hospital, National and Kapodistrian University of Athens.

CORRESPONDENCE TO Paraskevi Katsaounou 1rst ICU Clinic, "Evaggelismos" General Hospital, National and Kapodistrian University of Athens, 45-7 Ipsilandou str, 10676 Athens, Greece

Email:vkatsaounou@yahoo.com

\section{KEYWORDS}

electronic cigarette, respiratory function, airways resistance, respiratory impedance, airway inflammation

\section{INTRODUCTION}

In an era where traditional tobacco smoking is experiencing a decline, e-cigarette usage is dramatically increasing, attracting both former tobacco smokers and never smokers ${ }^{1,2}$. Although e-cigarette use has been widely reported to be experimented with as a smoking cessation tool, it still lacks the scientific evidence to be considered as one ${ }^{3}$.

E-cigarette heats and vaporizes a nicotine-containing liquid, which is delivered fast to the respiratory and central nervous system. While vaporized e-cigarette aerosol may contain fewer toxicants than conventional cigarette smoke, studies evaluating the e-cigarettes health effects and safety are still ongoing.
However, in cell lines, e-cigarette vapour increases oxidative stress, inflammation ${ }^{4,5}$, may influence susceptibility to virus infection $^{6}$ and induces DNA strand breaks and cell death ${ }^{7}$ on airway epithelial cells. It is also cytotoxic, induces apoptosis in fibroblats ${ }^{8}$, initiate inflammation at Kupffer ${ }^{9}$ and enthothelial ${ }^{10}$ cells, and alters vascular smooth muscle cells ${ }^{11}$. There is also an increasing number of studies in animal models implicating possible health effects. Namely, exposure to e-cigarette vaping results in immunomodulatory effects that are similar to those observed after exposure to conventional cigarette smoke, impairs pulmonary anti-bacterial and anti-viral defenses ${ }^{12}$, aggravates allergen-induced airway Inflammation and 
hyper-responsiveness ${ }^{13}$, induces toxicity, and oxidative stress.

The aforementioned studies indicate that e-cigarette use might have significant consequences on the human respiratory system. However, scientific data on health effects of e-cigarettes in humans are impressively limited. There are scarce case reports showing e-cigarette effects on the respiratory system ${ }^{14-5}$, and a few studies showing acute effect in aortic stiffness and blood pressure ${ }^{16-7}$. Although there are numerous studies addressing the effects of traditional cigarette $^{18-22}$ in respiratory physiology, very few are available concerning the same topic for e-cigarettes ${ }^{23-55}$. Vardavas et al reported an increase in lung resistance, impedance, and a decrease of $\mathrm{FeNO}^{23}$. Contrastingly, Schober et al and Marini et al reported a resultant increase of $\mathrm{FeNO}^{24}$. An amelioration of respiratory symptoms and lung function was reported after switching from regular cigarettes to e-cigarette in a small group of asthmatic smokers ${ }^{26}$.

Our study is designed: a) to investigate the acute effects of e-cigarette use in respiratory systems of smokers with obstructive airways diseases (Chronic Obstructive pulmonary disease (COPD) and asthma), "healthy" smokers, and healthy never smokers, and b) to compare the effect of a nicotine e-cigarette $(11 \mathrm{mg})$ to a nicotine-free one in healthy nonsmokers.

\section{METHODS}

\section{Study Population}

Seventy-six (76) adults participated in our study. Fifty-five (55) subjects were smokers recruited from our smoking cessation clinic (16 with COPD, 11 with asthma, 27 with no respiratory history) and 21 healthy nonsmokers. (nine of which used an e-cigarette containing $11 \mathrm{mg}$ nicotine and 12 a nicotine free e-cigarette). In this manuscript, we use the term "healthy" to connote those without any history and/or symptoms of any overt airway disease. All participants were naïve e-cigarette users but, were able to vape successfully during a pretest training.

Inclusion criteria for smokers were: a) age $>18$ years, b) smoking habit $>15$ cigarettes/day, c) No previous or current smoking cessation treatment, d) no history of exacerbations during last month, and e) ability to cooperate with the applied techniques for detecting airways inflammation and lung function testing. Exclusion criteria were: a) any bacterial or viral illness for the last 4 weeks b) ex-smoking, b) other acute or chronic respiratory disease, but asthma and COPD, c) chronic heart, liver, renal disease, or other serious disease, d) drug abuse, and e) pregnancy, lactation, malignancies, autoimmune, and immunodeficiency conditions.

\section{Study protocol}

Participants visited the lab 1-2 weeks after recruitment to complete the main protocol procedures. Food or drink consumption was not allowed for at least two hours before study measurements. Smoking abstinence was advised for at least 6 hours before measurements. No bronchodilators were taken for the previous 24 hours. The hospital's Ethics Committee approved the study protocol and all participants obtained informed consent.

Respiratory symptoms, vital signs, airways non-invasive inflammatory markers (exhaled NO and breath airways temperature), lung function test (airway resistance, specific airway conductance, single nitrogen breath test) were measured before and immediately after $10 \mathrm{~min}$ of ad lib use of an e-cigarette. The number of puffs was not statistically different among smokers and never smokers. However, never smokers who used the nicotine-free e-cigarette reported a greater number of puffs. The same brand of a first generation e-cigarette popular at the national level in Greece, was obtained from the same source, and used by all participants. The e-cigarette was recharged and refilled, according to the manufacturer's instructions, with the same commercially available flavorless liquid.

Clinical symptoms (cough, sore throat, dry mouth, eye irritation, palpitations, and nausea), vital signs (heart rate, oxygen saturation), pleasure feeling and the total number of puffs were recorded for each participant.

Airway inflammation assessment was performed by measurements of non-invasive exhaled markers - exhaled breath temperature (X-halo breath thermometer $\mathrm{X}$-halo, Delmedica, USA) and exhaled NO (Niox-MINO analyzer: Aerocrine AB. Aerocrine AB, P.O. Box 1024,SE-171 21 Solna, Sweden $)^{27}$

Lung function tests were also performed before and after 10 min of the e-cig use. Simple spirometry was performed with the Vmax apparatus (Vmax Encore 22, SensorMedics, Yorba Linda, CA, USA) using the "fast maneuver". The diffusing capacity for carbon monoxide (DLCO) was also determined by the single breath technique (Vmax Encore 22). Static Lung Volumes were determined by body plethysmography (Vmax Autobox Plethysmograph, SensorMedics, Yorba Linda, CA, USA). Predicted values of spirometry, static lung volumes and DLCO were from the European Community for Coal and Steel ${ }^{28}$. Airway resistance (Raw) and specific airway conductance (sGaw) were also assessed by the body plethysmography (Vmax Autobox). Predicted values were from Dubois et $\mathrm{al}^{29}$. The means of two or more acceptable tracings for each subject were reported. 
Finally, the single breath nitrogen test (SBN2T) was performed (Vmax Encore 22) for the assessment of the slope of phase III in order to evaluate small airways function. Subjects were asked to breathe to residual volume (RV) and immediately perform a slow maximal inspiration of oxygen followed by a slow $(\sim 0.5 \mathrm{l} / \mathrm{s})$ expiration to RV. Phase III slope was calculated as the best-fitted line through phase III. The reported values (DN2/L, \% pred) of phase III slope are means of two or more acceptable tracings. Normal values for phase III slope were from Buist and Ross ${ }^{1,30}$.

\section{Statistical analysis}

Data are expressed as mean ${ }_{-} \mathrm{SD}$, unless otherwise stated. For comparisons between groups Student's paired t-test, Student's t-test, Mann-Whitney rank sum test, Chi-square and Student's one-way ANOVA with Holm-Sidak's correction were used. A ps 0.05 value was considered as significant. Statistics were performed using the SigmaStat V3.5 and SigmaPlot V10.0 statistical software (Jandel Scientific, CA, USA).

\section{RESULTS}

Demographic characteristics of the study population groups and baseline spirometry data (FVC, \% pred, FEV1 \% pred FEV1/FVC, \%) and DLCO, \%pred are shown in Table 1. There were no differences between the groups of healthy smokers and never smokers, who did not differ by age, gender, and BMI. In contrast, COPD smokers were older, had a higher pack-years history and lower baseline spirometry values compared to the other smokers.

\section{Impact on symptoms}

Clinical symptoms reported immediately following $10 \mathrm{~min}$ of e-cig use are shown in Table 2 . The majority of healthy smokers, and never smokers using e-cigarette with nicotine concentrations predominantly reported a dry mouth and sore throat. Acute cough was reported by $69 \%$ of smokers with COPD, $55 \%$ of smokers with asthma, "healthy" smokers (68\%), and healthy never smokers following both use of $11 \mathrm{mg}$ and $0 \mathrm{mg}$ nicotine concentrations ( $44 \%$ and $50 \%$, respectively). Palpitations were reported by $46 \%$ of asthmatics using nicotine containing e-cigarette. Lower percentages of palpitations were reported by COPD patients (19\%), healthy smokers (36\%) and healthy never smokers $(33 \%)$. Nausea was reported (below $50 \%)$ in all groups after e-cig use.

\section{Effects on vital signs and airway inflammation}

Vital signs and airway inflammatory markers are shown in Table 3 . The $11 \mathrm{mg}$ nicotine e-cigarette caused a statistically significant $(\mathrm{p}<0.05)$ increase in heart rate in all subjects, except COPD patients. No changes in heart rate were detected following the use of the nicotine free device in non-smokers. No changes in arterial blood pressure were observed in all participants. A small but statistically significant decrease in oxygen saturation ( $\mathrm{SpO} 2)$ was noted following e-cigarette use in "healthy" smokers $(\mathrm{p}<0.001)$ and COPD smokers $(\mathrm{p}<0.05)$. Exhaled NO decreased following e-cigarette use in all subjects, but these changes were not statistically significant. Similarly, no statistically significant changes were noted in exhaled breath airway temperature.

\section{Changes in Lung Functions}

Lung function changes are presented in table 4. Baseline measurements (before e-cigarette use) showed an increased mean values of airways resistance (Raw) and decreased values of specific airways conductance (sGaw) in smokers with COPD and asthma compared with healthy smokers and never

Table 1: Study population characteristics and baseline lungfunction.

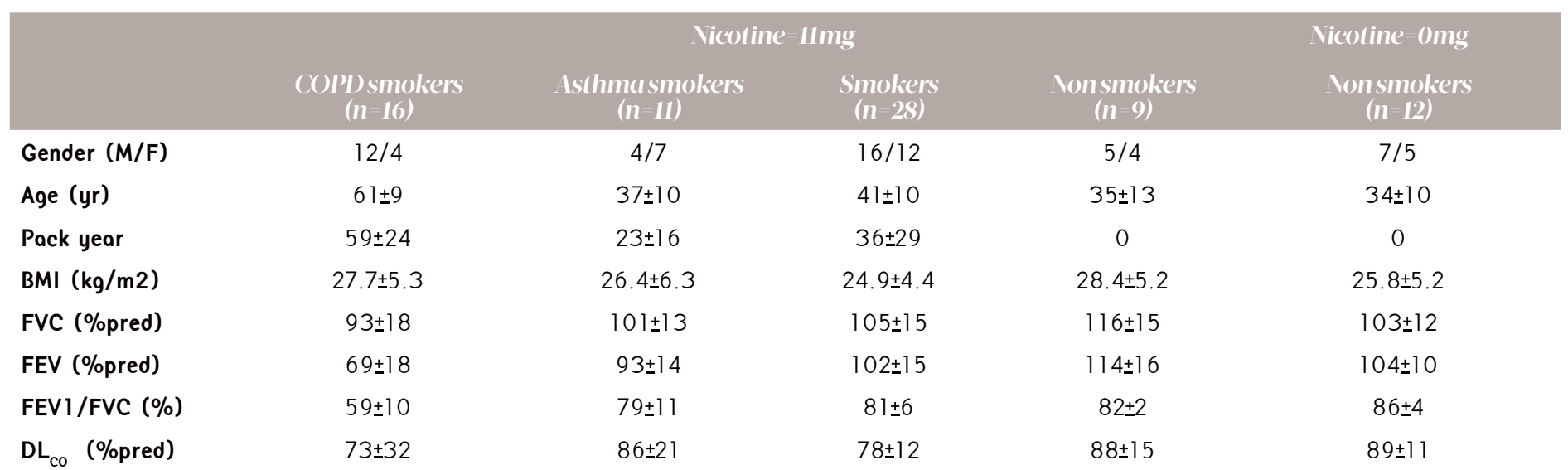

Values are expressed in mean \pm SD. M/F: Male/Female yr: years BMI: Body Mass Index FVC: Forced Vital Capacity FEV1: Forced Expiratory Volume in 1 second DLco: Diffusion Capacity of Carbon Monoxide \%pred: Percent of the predicted value. 
Research Paper

Table 2: Self-reported Symptoms reported post use of a single e cigarette containing $0 \mathrm{mg} / 1 \mathrm{mg}$ of nicotine.

\begin{tabular}{|c|c|c|c|c|c|}
\hline \multirow[b]{2}{*}{ Symptoms } & \multirow[b]{2}{*}{$\begin{array}{c}\text { COPDsmokers } \\
(n=16)\end{array}$} & \multicolumn{2}{|c|}{ Nicotine-11mg } & \multirow[b]{2}{*}{$\begin{array}{c}\text { Nonsmokers } \\
\qquad(\mathbf{n}=9)\end{array}$} & \multirow{2}{*}{$\begin{array}{c}\text { Nicotine } 0 \mathrm{mg} \\
\text { Nonsmokers } \\
(\mathrm{n}=12)\end{array}$} \\
\hline & & $\begin{array}{c}\text { Asthma smokers } \\
\qquad(n=11)\end{array}$ & $\begin{array}{c}\text { Smokers } \\
(n-28)\end{array}$ & & \\
\hline Acute Cough & 69 & 55 & 68 & 44 & 50 \\
\hline Sore throat & 69 & 82 & 61 & 67 & 33 \\
\hline Dry mouth & 81 & 91 & 79 & 89 & 67 \\
\hline Eye Irritation & 19 & 27 & 18 & 33 & 25 \\
\hline Palpitations & 19 & 46 & 36 & 33 & 17 \\
\hline Nausea & 31 & 36 & 25 & 22 & 50 \\
\hline Pleasure & 44 & 36 & 54 & 22 & 75 \\
\hline Puffs & $32 \pm 12$ & $43 \pm 28$ & $38 \pm 9$ & $33 \pm 13$ & $52 \pm 18$ \\
\hline
\end{tabular}

Symptoms are expressed as \% of the patients presenting the symptom Puffs are expressed as mean $\pm S D$

Table 3: Vital signs and markers of airway inflammation. Pre and post-use of ane cigarette

\begin{tabular}{|c|c|c|c|c|c|}
\hline & \multirow[b]{2}{*}{$\begin{array}{l}\text { COPD smokers } \\
(n=16)\end{array}$} & \multicolumn{2}{|c|}{ Vicotine $11 \mathrm{mg}$} & \multicolumn{2}{|c|}{ Vicotine $=0 m g$} \\
\hline & & $\begin{array}{c}\text { Asthmasmokers } \\
\qquad(n-11)\end{array}$ & $\begin{array}{c}\text { Smokers } \\
(n-28)\end{array}$ & $\begin{array}{l}\text { Nonsmokers } \\
\qquad(n-9)\end{array}$ & $\begin{array}{c}\text { Non smokers } \\
\left(\begin{array}{l}(n-12) \\
\text { 12 }\end{array}\right.\end{array}$ \\
\hline \multicolumn{6}{|l|}{$\mathrm{SpO}_{2}$} \\
\hline Pre & $96.4 \pm 1.9$ & $97.2 \pm 1.53$ & $98.2 \pm 1$ & $97.4 \pm 2.1$ & $98.4 \pm 0.9$ \\
\hline Post & $95.8 \pm 1.8^{*}$ & $96.6 \pm 1.36$ & $97.1 \pm 1.5^{* *}$ & $97 \pm 0.7$ & $98.4 \pm 0.5$ \\
\hline \multicolumn{6}{|l|}{ HR } \\
\hline pre & $76.0 \pm 11.2$ & $84.9 \pm 14.2$ & $75.2 \pm 9.8$ & $79.1 \pm 13.8$ & $80.4 \pm 9.3$ \\
\hline Post & $79.4 \pm 13.7$ & $93.5 \pm 15.1^{*}$ & $92.1 \pm 16.9^{* *}$ & $92.2 \pm 17.4^{*}$ & $78.8 \pm 9.0$ \\
\hline \multicolumn{6}{|l|}{ eNO } \\
\hline Pre & $12.7 \pm 6.4$ & $12.1 \pm 4.8$ & $11.7 \pm 10.2$ & $16.0 \pm 4.5$ & $13.3 \pm 8.3$ \\
\hline Post & $11.7 \pm 8.2$ & $10.6 \pm 4.6$ & $10.7 \pm 10.2$ & $14.7 \pm 4.6$ & $10.8 \pm 6.5$ \\
\hline \multicolumn{6}{|c|}{ Air Temp } \\
\hline Pre & $33.8 \pm 0.9$ & $33.4 \pm 1.1$ & $33.7 \pm 1.5$ & $34 \pm 1.5$ & $33.1 \pm 2.0$ \\
\hline Post & $34.2 \pm 1.5$ & $33.5 \pm 1.2$ & $34.1 \pm 0.7$ & $33.9 \pm 1.9$ & $32.7 \pm 3.1$ \\
\hline
\end{tabular}

Values are expressed as mean $\pm S D$

$p$ values: Comparison of pre and post smoking a single e-cigarette * $p<0.05,{ }^{* *} p<0.001$

$\mathrm{SpO}_{2}$ : Oxygen Saturation, HR: Heart Rate, eNO: exhaled Nitric Oxide, Air Temp: Airways Temperature

Table 4: SBN2 data, airway resistance (Raw), and special airway conductance (sGaw) pre-and post-use of an e cigarette

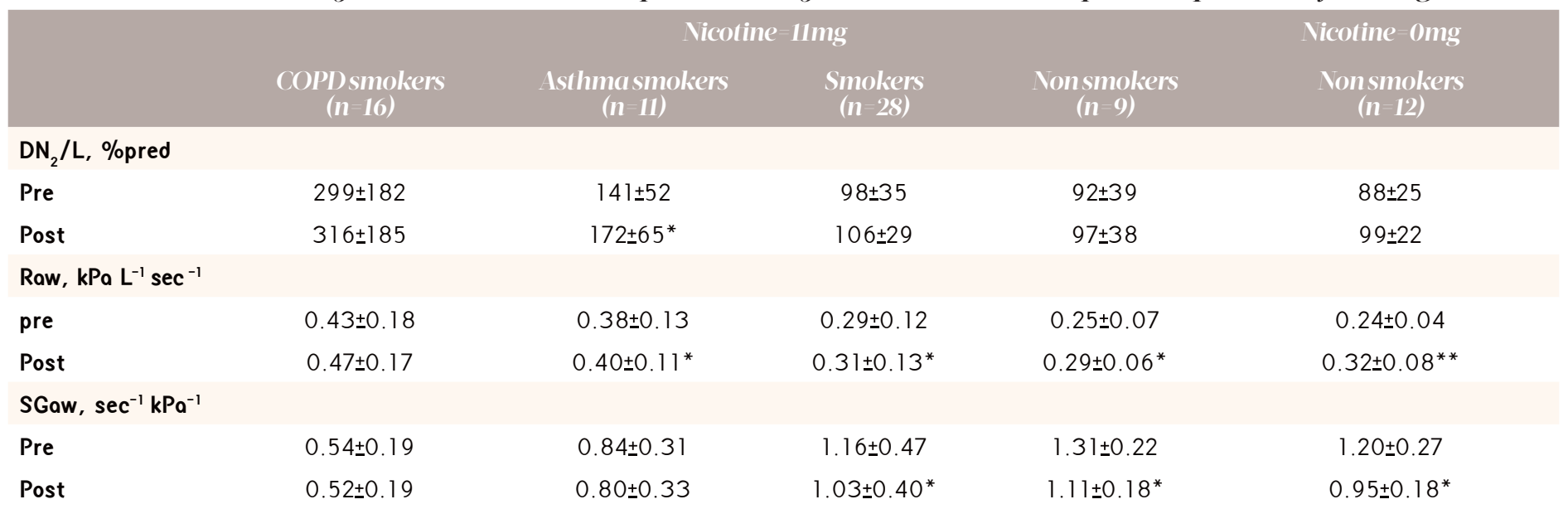

Values are expressed as mean $\pm S D$, obtained in sitting positions

$p$ values: Comparison of pre- and post- inhaling the content of an e-cigarette ${ }^{*} p<0.05{ }^{* *} p<0.001 \Delta N 2 / L$ : Slope of phase III Raw: Airway resistance sGaw: Specific airway conductance \%pred: percent of predicted 
Figure 1-Airway resistance pre-and post-inhaling the content of a single e cigarette. Box plot graphs for each of the groups tested. The end of the boxes define the 25th and $75 t h$ percentiles, with a line at the median and error bars defining the 10th and $90 t h$ percentiles.

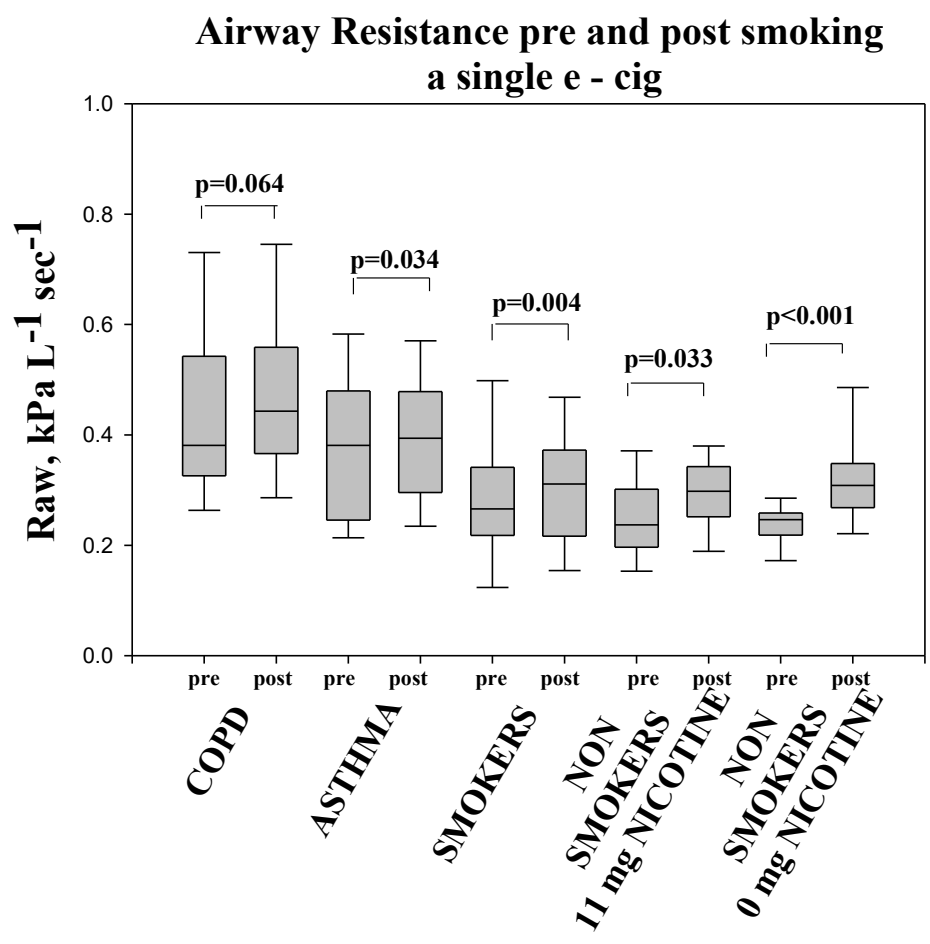

Figure 2- Specific airway conductance pre-and post-e cigarette use depicted withbox plot graphs for each of the groups.

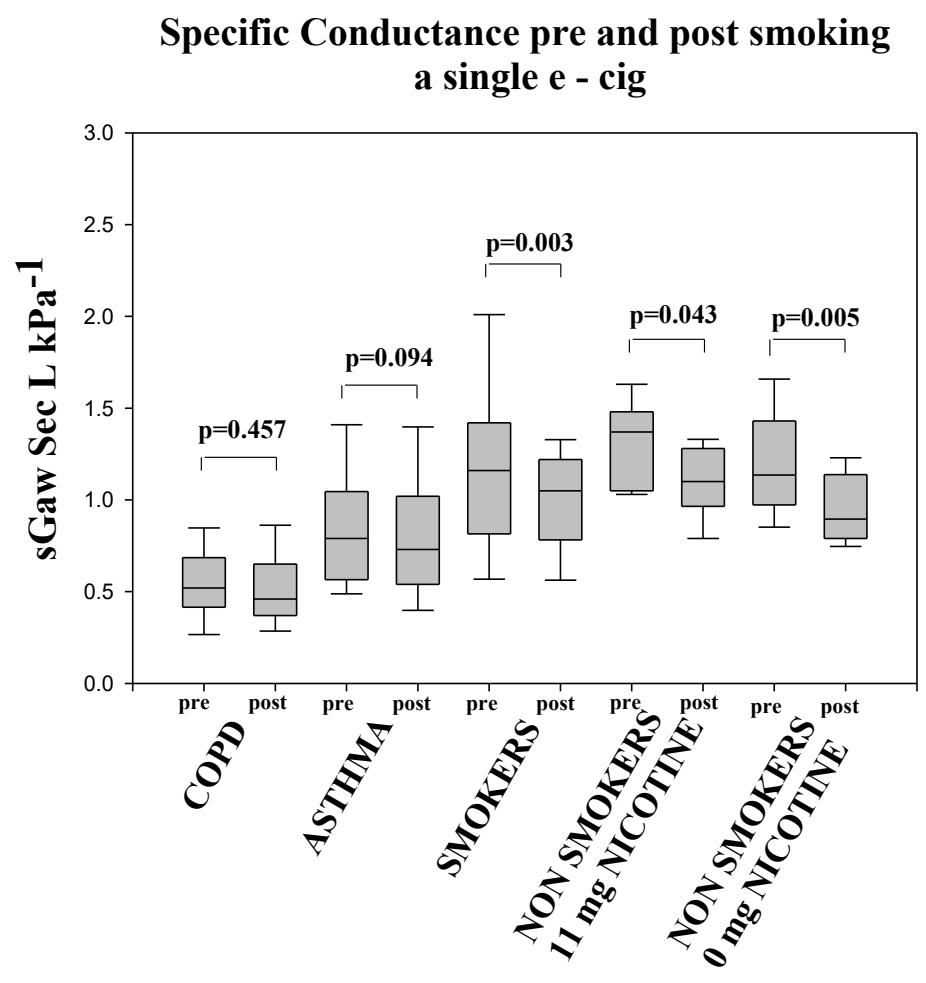

smokers. Following $10 \mathrm{~min}$ use of e-cigarette dynamic static lung volumes, and DLCO showed no statistically significant changes in all participants. However, there were significant changes detected in airways resistance (Raw) and specific airways conductance (sGaw) noted after e-cigarette use. A significant increase in airways resistance $(\Delta$ Raw) was detected in asthmatic $(\mathrm{p}=0.034)$ and healthy smokers $(\mathrm{p}=0.004)$. Strikingly, an increase in Raw was detected in never smokers after e-cigarette use both when nicotine was contained $(\mathrm{p}<0.005)$ or not $(\mathrm{p}<0.001)($ Fig .1$)$

A decrease in specific airways conductance (sGaw) was also detected in all groups but this change was statistically significant only in healthy subjects, both smokers $(\mathrm{p}<0.05)$ and never smokers $(\mathrm{p}<0.05)$. In healthy non-smokers, this decrease occurred using both nicotine and nicotine-free e-cigarette (Fig 2). sGaw was the only test were gender differences were found between "healthy" smokers.

Changes in Raw and sGaw were not statistically significant in smokers with COPD.

Evaluation of the small airways function by the single breath nitrogen test resulted in an increase of the slope of phase III curve (expressed as $\Delta \mathrm{N} 2 / \mathrm{L}, \%$ pred) following e-cigarette use in all groups. The slope of phase III curve was already increased at baseline measurements in both COPD $(p<0.001)$ and asthmatic $(p<0.05)$ smokers compared with healthy smokers. After use of the e-cigarette the slope of phase III curve significantly changed only in asthmatic smokers $(\mathrm{p}<0.01)$. A simple explanation for the latter is that dysfunction of asthmatic smokers' small airways was less than this of COPD patients. It could also be a sign of increased bronchial hyperactivity since research in animal models has already showed that e-cigarette aggravates allergen-induced airway Inflammation and hyper-responsiveness ${ }^{13}$.

\section{DISCUSSION}

The assessment of the acute effects of e-cigarette use on the respiratory system and airway physiology in non-healthy (COPD, Asthma) smokers, "healthy" smokers, and never smokers has not been the focus of extensive research so far. Our study exposes the effect of short-term use of e-cigarette on respiratory symptoms, vital signs, airway inflammation and lung function by specifically assessing airway physiology in smokers with asthma and COPD, "healthy" smokers, and healthy never smokers.

Our outcomes are in accordance with a previously published study on short-term effect of e-cigarette use on airways resistance $^{23}$. The take home message is that short-term (10 
min) use of an e-cigarette has an acute effect on the respiratory system in smokers -a significant increase in airway resistance (Raw). The effect was more profound in both asthmatic and "healthy" smokers. More striking is the increase in Raw in healthy never smokers despite using an e-cigarette without nicotine.

Against the backdrop of other studies, the single breath nitrogen test to further assess the effect of e-cig on small airways was used for the first time to measure and capture short term effect of e-cigarette both in smokers with COPD and asthma. The slope of phase III of the single breath test is used as an index of small airway dysfunction and distribution of ventilation. It has been previously shown that the baseline slope of phase III is increased higher than normal in patients with $\mathrm{COPD}^{32}$. Our result reaffirms the increased slope of phase III in COPD and the normal slope of "healthy" smokers and non-smokers cited in the aforementioned study ${ }^{32}$. The significant increase immediately after the use of e-cigarette in the slope of phase III experienced only in asthmatic smokers might reflect early small airways impairment and deterioration of homogeneity of ventilation in this population.

In contrast with previous studies, we did not detect significant changes in $\mathrm{FeNO}^{5,23}$. This may be due to the short time of exposure or the small number of observations.

Interestingly, lung function impairment, as reflected in Raw and sGaw, was demonstrated regardless of the nicotine concentration of the e-cigarette. As animal models have indicated negative effects after exposure to e-cigarette liquids containing aromatics ${ }^{5,33}$, it would be of interest to test the effect of these constituents in humans in future studies.

We identified that short-time e-cigarette use led to participants cough regardless of nicotine concentration. These responses probably represent vagal mediated protective reflexes as they promote proximal deposition of vaporized particles and their subsequent ejection from the lungs by cough and mucociliary clearance. Our results are in line with previous studies showing that e-cigarettes may produce mouth, throat irritation, and dry cough, a factor that may be moderated however by the user's experience in vaping ${ }^{8,36}$.

Palpitations were reported by participants who used the nicotine containing e-cigarette reflecting nicotine's properties. However, a smaller number of COPD patients vs. other groups reported palpitations caused by the e-cigarette. This might be explained by the fact that the COPD patients had a higher number of pack years compared to other groups in our study. Most of studies addressed the effect of e-cigarette in heart rate, blood pressure or heart beat instead of palpitations. Increased heart rate is a common finding ${ }^{7,16}$. Following short time e-cigarette use, a statistically significant decrease in oxygen saturation ( $\mathrm{SpO} 2$ ) was noted in COPD patients who had already a lower baseline level compared with the other smoker groups. Therefore, increased awareness should be raised concerning blood oxygen desaturation and tachycardia caused by long-term e-cigarette use in susceptible populations (i.e. COPD) with hypoxia and/or cardiac arrhythmias.

There is significant debate around the individual and population implications of e-cigarette use ${ }^{39-45}$.

Our study is not without limitations. Foremost, our participants are all naïve vapers. Although they were recruited after a pretest training, little differences in vaping are apparent. Moreover, we used a first generation e-cigarette. It will be interesting to see if our results can be replicated with newer generation's e-cigarettes in future studies. Although the e-cigarette used was popular at the national level and purchased from the same source, variability of nicotine concentrations and liquid ingredients cannot be excluded. Lastly, a larger sample size, inclusion of testing all e-cigarette ingredients, a newer generation e-cigarette, chronic use and experienced users, would be interesting to be addressed in future studies as they could add important information to our findings. Further research is needed towards these directions.

\section{CONCLUSIONS}

This study has shown that short-term use of e-cigarette has an acute effect on the respiratory system. Smokers with obstructive airways disease and mainly smokers with asthma may exhibit deterioration of respiratory symptoms and lung function impairment following use of an e-cigarette. According to our study, effects on airways could not be attributed to nicotine. Further studies are needed to unfold the short and long-term health effects of e-cigarettes to support the decisions of policymakers, health care providers, and consumers.

\section{REFERENCES}

1. Vardavas CI, Filippidis FT, Agaku IT. Determinants and prevalence of e-cigarette use throughout the European Union: a secondary analysis of 26566 youth and adults from 27 Countries. Tob Control 2015 Sep; 24(5):442-8.

doi: 10.1136/tobaccocontrol-2013-051394. Epub 2014 Jun 16.

2. Filippidis FT, Laverty AA, Gerovasili V, Vardavas CI. Two-year trends and predictors of e-cigarette use in 27 European Union member states. Tob Control. 2016 May 24. doi: 10.1136/tobaccocontrol-2015-052771.

3. Kalkhoran S, Glantz SA. E-cigarettes and smoking cessation in real world and clinical settings: a systematic review and meta-analysis. Lancet Respir Med 2016. doi: 10.1016/S2213-2600(15)00521-4.

4. Scheffler S, Dieken H, Krischenowski O, Förster C, Branscheid D, Aufderheide M.Evaluation of E-cigarette Liquide vapor and mainstream cigarette smoke after direct exposure of primary human 
bronchial epithelial cells. Int J Environ Res Public Health. 2015 Apr 8;12(4):3915-25.

doi: 10.3390/ijerph120403915.

5. Scheffler S, Dieken H, Krischenowski O, Aufderheide M.Cytotoxic Evaluation of e-Liquid Aerosol using Different Lung-Derived Cell Models. Int J Environ Res Public Health. 2015 Oct 5;12(10):1246674 .

doi: 10.3390/ijerph121012466.

6. Wu Q, Jiang D, Minor M, Chu HW. Electronic cigarette liquid increases inflammation and virus infection in primary human airway epithelial cells. PLoS One. 2014 Sep 22; 9(9):e108342.

7. Vicky Yu, Mehran Rahimy, Avinaash Korrapati, Yinan Xuan, Angela E Zou, Aswini R Krishnan, Electronic cigarettes induce DNA strand breaks and cell death independently of nicotine in cell lines. Oral oncology (2016). doi: 10.1016/j.oraloncology.2015.10.018.

8. Sancilio S, Gallorini M, Cataldi A, di Giacomo V. Cytotoxicity and apoptosis induction by e-cigarette fluids in human gingival fibroblasts. Clin Oral Investig. 2016;20:477-483. doi: 10.1007/s00784-015-1537-

9. Rubenstein DA, Hom S, Ghebrehiwet B, Yin W. Tobacco and e-ci garette products initiate Kupffer cell inflammatory responses. Mol Immunol. 2015 Oct; 67(2 Pt B):652-60.

10. Schweitzer KS, Chen SX, Law S, Van Demark M, Poirier C, Justice MJ, Hubbard WC, Kim ES, Lai X, Wang M, et al. Endothelial disruptive proinflammatory effects of nicotine and e-cigarette vapor exposures. Am J Physiol Lung Cell Mol Physiol. 2015;309:L175187. doi: 10.1152/ajplung.00411.2014.

11. Yoshiyama S, Chen Z, Okagaki T, Kohama K, Nasu-Kawaharada R, Izumi T, Ohshima N, Nagai T, Nakamura A. Nicotine exposure alters human vascular smooth muscle cell phenotype from a contractile to a synthetic type. Atherosclerosis. 2014; 237:464-470. doi: 10.1016/j.atherosclerosis.2014.10.019.

12. Sussan TE, Gajghate S, Thimmulappa RK, Ma J, Kim JH, Sudini K, Consolini N1, Cormier SA, Lomnicki S, Hasan F, Pekosz A, Biswal S.Exposure to electronic cigarettes impairs pulmonary anti-bacterial and anti-viral defenses in a mouse model. PLoS One.2015 Feb 4; 10(2):e0116861.

13. LimHB, Kim SH. Inhallation of e-Cigarette Cartridge Solution Aggravates Allergen-induced Airway Inflammation and Hyperresponsiveness in Mice. Toxicol Res. 2014 Mar; 30(1):13-8. doi: 10.5487/TR.2014.30.1.013

14. Thota D, Latham E. Case report of electronic cigarettes possibly associated with eosinophilic pneumonitis in a previously healthy active-duty sailor. J Emerg Med. 2014 Jul; 47(1):15-7.

15. Hureaux J, Drouet M, Urban. A case report of subacute bronchial toxicity induced by an electronic cigarette. Thorax. 2014 Jun; 69(6):596-7

16. Ioakeimidis N, Vlachopoulos C, Tousoulis D. Efficacy and Safety of Electronic Cigarettes for Smoking Cessation: A Critical Approach. Hellenic J Cardiol. 2016 Jan-Feb; 57(1):1-6.

17. Cooke WH, Pokhrel A, Dowling C, Fogt DL, Rickards CA. Acute inhalation of vaporized nicotine increases arterial pressure in young non-smokers: a pilot study. Clin Auton Res. 2015 Aug; 25(4):26770 .

doi: 10.1007/s10286-015-0304-z. Epub 2015 Aug 12

18. Kougias M, Vardavas CI, Anagnostopoulos N, Matsunaga Y, Tzwrtzi A, Lymberi M, Connolly GN, Behrakis PK. The acute effect of cigarette smoking on the respiratory function and FENO production among young smokers. Exp Lung Res. 2013 Oct; 39(8):359-64 doi: 10.3109/01902148.2013.830654.

19. Higenbottam T, Hamilton D, Feyerband C, Clark TJ Acute effects of smoking a single cigarette on the airway resistance and the maximal and partial forced expiratory flow volume curves. Br J Dis Chest.1980 Jan; 74(1):37-46.

20. McDermott M, Collins MM. Acute effects of smoking on lung airways resistance in normal and bronchitic subjects. Thorax 1965; 20:562-9.

21. Suzuki S, Sasaki H, Takishima T. Effects of smoking on dynamic compliance and respiratory resistance. Arch Environ Health. 1983 May-Jun; 38(3):133-7.

22. Costello JF, Sudlow MF, Douglas NJ, Flenley DC. Acute effects of smoking tobacco and a tobacco substitute on lung function in man. Lancet.1975 Oct 11; 2 (7937):678-81.

23. Vardavas CI, Anagnostopoulos N, Kougias M, Evangelopoulou V, Connolly GN, Behrakis PK. Short-term pulmonary effects of using an electronic cigarette: impact on respiratory flow resistance, impedance, and exhaled nitric oxide. Chest 2012 Jun; 141(6):14006.

doi: 10.1378/chest.11-2443. Epub 2011 Dec 22.

24. Marini S, Buonanno G, Stabile L, Ficco G. Short-term effects of electronic and tobacco cigarettes on exhaled nitric oxide. Toxicol Appl Pharmacol. 2014 Jul 1;278(1):9-15. doi: 10.1016/j.taap.2014.04.004.

25. Wolfgang Schober, Katalin Szendrei, Wolfgang Matzen, Helga Osiander-Fuchs,Dieter Heitmann, Thomas Schettgen, Use of electronic cigarettes (e-cigarettes) impairs indoor air quality and increases $\mathrm{FeNO}$ levels of e-cigarette consumers. International journal of hygiene and environmental health $2014 \mathrm{Jul} ; 217(6): 628$ 37.

doi: 10.1016/j.ijheh.2013.11.003. Epub 2013 Dec 6.

26. Polosa R1, Morjaria J2, Caponnetto P3, Caruso M4, Strano S5, Battaglia E6, Russo 7 Effect of smoking abstinence and reduction in asthmatic smokers switching to electronic cigarettes: evidence for harm reversal. Int J Environ Res Public Health. 2014 May 8; 11(5):4965-77. doi: 10.3390/ijerph110504965.

27. ATS/ERS recommendations for standardized procedures for the online and offline measurement of exhaled lower respiratory nitric oxide and nasal nitric oxide, 2005. Am J Respir Crit Care Med. 2005 Apr 15;171(8):912-30

28. Quanjer $\mathrm{PhH}$. Standardized lung function testing. Report Working Party "Standardization of Lung Function Tests", European Community for Coal and Steel. Eur Respir J 1993; 6 (Suppl. 16): $1-100$.

29. Dubois AB, Bothello SJ, Comroe JH Jr. A new method of measuring airway resistance in man using a body plethysmograph. Values in normal subjects and in patients with respiratory disease. $\mathrm{J}$ Clin Invest 1956; 35: 327-335. doi: 10.1172/JCI103282.

30. Anthonisen NR, Danson J, Robertson PC, Ross WR. Airway closure as a function of age. Resp Physiol 1970; 8: 58-65.

31. Buist AS, Ross BB. Predicted value for closing volumes using a modified single breath nitrogen test. Am Rev Respir Dis 1979; 107: 744-751 doi: 10.1164/arrd.1973.107.5.744

32. Gennimata SA, Palamidas A, Karakontaki F, Kosmas EN, Koutsoukou A, Loukides S, Koulouris NG. Pathophysiology of evolution of small airways disease to overt COPD. COPD. 2010 Aug;7(4):269-75

33. Sherwood CL, Boitano S Airway epithelial cell exposure to distinct e-cigarette liquid flavorings reveals toxicity thresholds and activation 


\section{Research Paper}

of CFTR by the chocolate flavoring 2,5-dimethypyrazine. Respir Res. 2016 May 17; 17(1):57 doi: 10.1186/s12931-016-0369-9.

34. Lerner CA, Sundar IK, Yao H, Gerloff J, Ossip DJ, McIntosh S, Robinson R, Rahman I. Vapors produced by electronic cigarettes and e- juices with flavorings induce toxicity, oxidative stress, and inflammatory response in lung epithelial cells and in mouse lung. PLoS One. 2015 Feb 6;10 (2).

doi: 10.1371/journal.pone.0116732. eCollection 2015.

35. Constantinos G., Bibli S, Pavlidou A,Katsaounou P, Kalomenidis I, Zakynthinos S, Papapetropoulos A. Comparison of the effects of e-cigarette vapor vs cigarette smoke on lung function and inflammation in mice. International Congress 2015 - Emerging data on e-cigarettes and their health hazards.

36. Carl D. D’Ruiz, Donald W. Graff, X. Sherwin Yan. Nicotine delivery, tolerability and reduction of smoking urge in smokers following short-term use of one brand of electronic cigarettes. BMC Public Health. 2015; 15: 991.

37. Dicpinigaitis PV, Lee Chang A, Dicpinigaitis AJ, Negassa A Effect of e-Cigarette Use on Cough Reflex Sensitivity. Chest. 2016 Jan;149(1):161-5.

38. Dicpinigaitis PV, Lee Chang A, Dicpinigaitis AJ, Negassa A. Effect of Electronic Cigarette Use on the Urge-to-Cough Sensation. Nicotine Tob Res. 2016 Aug;18(8):1763-5

39. McNeill A, Brose LS, Calder R, et al. E-cigarettes: an evidence update: a report commissioned by Public Health England. Public Health England, 2015.

40. PisingerC1. Why public health people are more worried than excite d over e-cigarettes. BMC Med. 2014 Dec 9;12: 226. doi: 10.1186/s12916-014-0226-y.

41. Green SH, Bayer R, Fairchild AL Evidence, Policy, and E-Cigarettes-Will England Reframe the Debate? N Engl J Med. 2016 Apr 7;374(14):1301-3

42. McKee M, Capewell S. Evidence about electronic cigarettes: a foundation built on rock or sand? BMJ 2015; 351: h4863 doi: 10.1056/NEJMp1601154.

43. E-cigarettes: Public Health England's evidence-based confusion. Editorial. Lancet 2015 Aug 29; 386(9996):829 doi: 10.1016/S0140-6736(15)00042-2.

44. Lundbäck B, Katsaounou P, Lötvall J. The up-rise in e-cigarette use - friend or foe? Respir Res. 2016 May 17; 17(1):52. doi: 10.1186/s12931-016-0371-2.

45. Bell K, Keane H. All gates lead to smoking: the 'gateway theory', e-cigarettes and the remaking of nicotine. Soc Sci Med. 2014 Oct; 119: 45-52.

doi: 10.1016/j.socscimed.2014.08.016. Epub 2014 Aug 15.

CONFLICT OF INTEREST The authors have completed and submitted the ICMJE Form for Disclosure of Potential Conflicts of Interest and none were reported.

FUNDING

There was no source of funding for this research.

PROVENANCE AND PEER REVIEW

Not commissioned;

externally peer reviewed 